\title{
UNA HISTORIA DE ARAGÓN EN LA HISTORIA: DEL REINO Y CORONA A LA MONARQUÍA HISPÁNICA (SIGLOS XI-XVI)
}

\author{
Héctor Clemente Pérez* \\ UNIVERSIDAD DE ZARAGOZA \\ Universidad Complutense de MADRID
}

\begin{abstract}
RESUMEN
El artículo que aquí se presenta pretende ofrecer una perspectiva diacrónica y global del papel aragonés en el desarrollo político de la península ibérica. Desde su expansión como reino autónomo, la imagen de Aragón fue evolucionando hasta supeditarse a la hegemonía castellana, y finalmente la supresión borbónica. Sin embargo, a lo largo de estas páginas, trataremos de analizar la importancia que tuvo Aragón, tanto en la evolución de la Reconquista, como después, en la construcción de la llamada Monarquía Católica o Monarquía Hispánica.
\end{abstract}

PALABRAS CLAVE: Aragón, Reino y Corona, Monarquía Hispánica, supeditación castellana, imagen unitaria

*hectorcedrillas@hotmail.com 


\title{
A HISTORY OF ARAGON IN HISTORY: FROM KINGDOM AND CROWN TO THE HISPANIC MONARCHY (XI-XVI CENTURIES)
}

\author{
Héctor Clemente Pérez* \\ UniversidAD DE ZARAGOZA \\ Universidad Complutense de Madrid
}

\begin{abstract}
The article presented here aims to offer a diachronic and global perspective of the Aragonese role in the political development of the Iberian Peninsula. The image of Aragon was evolving since its expansion as an autonomous kingdom, until it was subject to the Castilian hegemony, and finally the Bourbon suppression. However, through these pages, we will try to analyze the importance that Aragon had, both in the evolution of the Reconquest, and later, in the construction of the so-called Catholic Monarchy or Hispanic Monarchy.
\end{abstract}

KEYWORDS: Aragon, Kingdom and Crown, Hispanic Monarchy, Castilian supeditation, unitary image

\footnotetext{
*hectorcedrillas@hotmail.com
} 


\section{INTRODUCCIÓN}

Existe un conocido aforismo, atribuido al jurista aragonés Bartolomé Leonardo de Argensola (1562-1631), que señala cómo en "Aragón hubo antes leyes que reyes" . Esta sentencia, estudiada a través de la justificación de los llamados Fueros de Sobrarbe ${ }^{2}$, pretendía retrotraer en el tiempo la formación de Aragón, y situar el poder del monarca por debajo de la tradición foral aragonesa. Precisamente, su primera referencia la establece otro cronista del reino de Aragón, Jerónimo de Blancas y Tomás (¿? -1590), en cuya obra, Aragonensium rerum commentarii (1588), explicaba el origen de las instituciones aragonesas, especialmente la del Justicia ${ }^{3}$, en un contexto de tensas relaciones entre Aragón y su monarca, que culminarían en las conocidas como Alteraciones de Aragón de 15914.

Este aforismo, y su argumentario, me permiten situar la línea cronológica y analítica propuesta para este artículo, donde analizaremos el desarrollo de Aragón desde sus orígenes hasta el reinado de Felipe II. Los motivos de ello radican en dos ideas, que conforman a su vez los dos objetivos a perseguir: por un lado, no sobrepasar los límites de este artículo, al entenderse como una cronología perfectamente definida en la que podemos observar la formación de Aragón, su crecimiento y su evolución, hasta alcanzar un momento de declive o sometimiento de sus instituciones, dentro de una entidad superior, como fue la Monarquía Hispánica. Por otro lado, a través de los hechos, las fuentes de la época y recientes estudios, obtendremos una perspectiva clara de la importancia que tuvo Aragón, su influencia para consigo misma y dentro del entorno peninsular, incluso en el progreso de otros reinos limítrofes, como Francia o Navarra, frente a la tradicional perspectiva de una entidad periférica y subordinada a Castilla.

\section{EL ORIGEN DEL REINO DE ARAGÓN: DE SANCHO III A ALFONSO I}

Para situarnos en los momentos iniciales de la entidad política que resultará ser Aragón debemos remontarnos al primer tercio del siglo XI, y más concretamente a un reinado de gran relevancia en la posterior confi-

1. J. López Medel (2016), 91.

2. B. Martínez y Herrero (1866); R. E. Giesey (1968).

3. J. DE Blancas (1588).

4. L. Leonardo de Argensola (1808); J. Gascón Pérez (2010). 
guración peninsular, el de Sancho III el Mayor (1004-1035). Ya fuese con su política matrimonial o la expansiva, lo cierto es que en la figura del monarca navarro se concentró el poder cristiano ibérico, desde el noroeste de la Península hasta la antigua Marca Hispánica carolingia. Con su muerte, sin embargo, todo el extenso territorio de reinos y condados fue repartido entre sus cuatro hijos, García, Fernando, Gonzalo y Ramiro, siendo este último el principal para nuestra historia, pues recibió el área "comprendida entre Matidero, en Sobrarbe, y Vadoluengo, en la linde de Navarra". Las tierras que habían sido ocupadas por Sancho III quedarían en manos del "bastardo" Ramiro Sánchez, cuya herencia conformaría el futuro territorio del reino de Aragón ${ }^{6}$.

Este primer "régulo" quedaba sujeto al poder de su hermano, el rey de Navarra, García Sánchez III $^{7}$. A pesar de ello, comenzaría una política expansiva que conseguiría conformar una progresiva autonomía, e incluso, en documentos navarros de ese momento, ya se intitularía a Ramiro Sánchez como "rey". Así a este "proto-rey", de origen pamplonés, le seguirían cuatro más: Sancho Ramírez (1063-1094), quien inició la expansión territorial y la configuración del sistema feudal aragonés, y en cuya nomenclatura todavía encontramos esa vinculación navarra; Pedro I (1094-1114), que conquistó importantes plazas como Huesca o Barbastro, en 1096 y 1110, respectivamente, consideradas por algunos autores como batallas entroncadas con el espíritu de las Cruzadas9. Tras su muerte le sucedió Alfonso I (1114-1134), en cuyo reinado se ocupó Zaragoza (1118), y se acabó consolidando la sociedad señorial, cristalizada a través de linajes militares y órdenes religiosas, que determinarían un proceso expansivo tan rápido, y también serían claves tras su muerte. En el verano de 1134, durante el sitio de Fraga, el monarca resultaría herido, y moriría apenas unos meses después. En su testamento, legaba todo a las órdenes militares ${ }^{10}$, lo que causó una gran confusión entre la nobleza, generando una crisis, que sería incluso aprovechada por Navarra para separarse del poder aragonés. Las élites feudales forzaron a su hermano, Ramiro, a salir del celibato para conseguir una descendencia que pusiera fin a los problemas. Con ello Aragón

5. J. F. Utrilla (2005), 312.

6. G. Martínez Díez (2004), 177.

7. P. SÉNAC (2000), 293.

8. Ibidem, 289.

9. M. González Jiménez (2000), 171-174.; F. García Fitz y F. Novoa Portela (2015).

10. A. Ubieto Arteta (1987), 69-70. 
entró en una nueva etapa, que supuso, a su vez, un punto de inflexión para los territorios que lo rodeaban a ambos lados del Pirineo.

\section{LA CRUZ Y EL MAR: LA CORONA DE ARAGÓN}

En agosto de 1150, se desposan, en la catedral de Lérida, Petronila (11361172), hija del todavía "rey, señor y padre en el citado reino [Aragón]"11, y Ramón Berenguer IV, conde de Barcelona y príncipe de Aragón (11371162), lo que supuso un cambio en el desarrollo de ambos territorios: tras el matrimonio, la política de conquista se extendió a la zona oriental aragonesa y al sur de los condados de Barcelona, con el fin de completar este ámbito y abrir una vía al territorio bajo aragonés ${ }^{12}$. El heredero de esta unión, Alfonso II (1162-1196), será considerado el primer titular de la conformada Corona de Aragón, pero además también será el primer "rey de Aragón": hasta ese momento, los monarcas se intitulaban como "rey de los aragoneses", como se aprecia en los documentos de Alfonso I, quien también se designa como "rey de los pamploneses"13. Cuando Alfonso II conquista el territorio turolense, y funda la villa de Teruel en 1172, define ya las fronteras de un territorio equiparable a otros reinos que le rodean, y desde ese momento firmará los documentos como señor de dos entidades completas, rey de Aragón y conde de Barcelona ${ }^{14}$.

Avanzamos al siglo XIII, en cuyo período destacan dos monarcas, Pedro II y Jaime I. Por un lado, Pedro II (1196-1213), que será coronado por el papa en Roma en 1204; aunque de su reinado debemos resaltar la batalla de Muret, defendiendo los territorios ultrapirenaicos, y en la cual morirá ${ }^{15}$. La derrota del 12 de septiembre de 1213 en Muret supuso la pérdida de una oportunidad de expansión en una Francia "todavía no formada"16, y diluyendo lo que algunos autores llaman la "Gran Corona de Aragón"17.

11. Ibidem, 144-145.

12. J. F. Utrilla (2005), 361 y ss.

13. Archivo Municipal de Huesca (AMH), doc. 7r. Alfonso I el Batallador concede al monasterio de San Ponce de Tomeras, a su hermano Ramiro y al abad don Pedro unas casas en Monzón, julio 1105. En R. ArCo (1930), 75.

14. Archivo Municipal de Zaragoza (AMZ), Colección Diplomática, Reales, Carpeta de conservación R-7. Privilegio real de Alfonso II, confirmando los fueros, usos y donaciones de Ramón Berenguer IV, Ramiro II y Alfonso I, agosto de 1162.

15. M. Roquebert (2002).

16. D. J. Sмith (2014), 76 y ss.

17. M. Alvira Cabrer, L. Mace y D. J. Smith (2009).

(C) Baetica. Estudios Historia Moderna y Contemporánea, 39, 2019, 75-92. Facultad de Filosofía y Letras, Universidad de Málaga. Departamento de Historia Moderna y Contemporánea 
Ello obligará a su sucesor, Jaime I, a olvidar su expansión francesa, lo que supuso un absoluto cambio en la historia ulterior de Francia y Aragón ${ }^{18}$. En este sentido, el reinado de Jaime I (1213-1276) se centrará en una nueva fase de la Reconquista, el Levante, siendo tres los tratados entre Castilla y Aragón, que acabarán definiendo la política de ambas Coronas: los tratados de Tudilén (1159) y Cazola (1179) establecían los límites sobre los cuales tenían derecho de ocupación cada monarca, y serán completados con el tratado de Almizra, de 1244, ya en el reinado del Conquistador, que, con el tiempo, supondrá un enfrentamiento con Castilla por el dominio murciano ${ }^{19}$. Con ello, y culminada la ocupación de Valencia, se cerraban las posibilidades de expansión aragonesa en la Península. A partir de ese momento, Aragón ejecutará una política marítima, en las Baleares, conquista definida por el propio monarca como "tan gloriosa empresa que en la memoria de cien años acá no tiene semejante" 20 ; las islas de Córcega, en menor medida, y sobre todo Cerdeña; Nápoles y Sicilia, y el breve período de ocupación de los ducados de Atenas y Neopatria.

De esta impresionante expansión debemos destacar dos ideas: por un lado, una mentalidad moderna, o, como poco, diferente del aún discurso reconquistador de Castilla (Portugal realizará lo propio con su expansión mercantil hacia África tras ocupar los últimos puestos del Algarve en 1249). Por otro lado, junto a la conquista surge también un discurso recíproco, en tanto a la defensa por parte de la población sometida. En Córcega aparecerá un dicho popular: "Furat chie venit dae su mare"21, y que podría traducirse como "todo lo malo viene del mar", o la que ofrece Ramona Onnis: "ceux qui viennent de la mer sont des voleurs" 22 , es decir, "los que vienen del mar son ladrones".

La Corona de Aragón iniciará este proceso expansivo por el Mediterráneo, mientras se generaban tensiones entre los grupos nobiliarios que se negaban a "passar el mar" 23 . Este rechazo se plasmará en el origen de grupos como la Unión Aragonesa de 1287, que conseguiría el llamado Privilegio de la Unión, abriendo un primer enfrentamiento entre la nobleza y las instituciones del Reino. Frente a estas tensiones internas, la extensión aragonesa, desde la

18. M. Alvira Cabrer (2010), 85-112.

19. Á. L. Molina (1997).

20. J. M. QuadRAdo (1850), 168.

21. R. ONNIS (2016), 37.

22. Ibidem.

23. J. F. Utrilla Utrilla (2009), 207. 
península ibérica hasta el Mediterráneo oriental, será exaltada por algunos cronistas, como Bernat Desclot, quien apuntaba cómo el almirante Roger de Lauria (1245-1305) replicaría al conde de Foix, emisario francés:

Señor, no solo no pienso que galera u otro bajel intente navegar por el mar sin salvoconducto del rey de Aragón, ni tampoco galera o leño, sino que no creo que pez alguno intente alzarse sobre el mar si no lleva un escudo con la enseña del rey de Aragón en la cola para mostrar el salvoconducto del rey aragonés ${ }^{24}$.

En este hecho, de dudosa veracidad, se observa, sin embargo, el discurso de la pugna franco-aragonesa por el dominio del Mediterráneo. No obstante, en la expansión del siglo XIII, Aragón vivirá un paralelismo al caso, que más adelante estudiaré, de "Castilla-Monarquía Hispánica", cuando se produzca una metonimia "Cataluña-Corona de Aragón", en la que se impondrán unos rasgos puramente económicos para designar una imagen conjunta: dentro de la Corona peninsular había población aragonesa, valenciana y catalana, cuyos intereses comerciales van a ser, en gran medida, los que fomenten esta conquista, siendo el término "catalán", con sus variantes y discursos, el que aparezca como elemento generalizador.

Será desde 1300 , con la ya predominante presencia comercial en el Mediterráneo, cuando surja la imagen perversa del "catalán", que se hará extensible a la imagen de toda la Corona, especialmente con la ocupación de Atenas y Neopatria, a cargo del ejército mercenario de la "Gran Compañía Catalana”. Tal como relata la llamada Crónica catalana o Crónica de Ramón Muntaner del siglo XIV, el ejército almogávar vengó la muerte de Roger de Flor ocupando y saqueando Grecia, por lo que el término "catalán" quedó vinculado a todo habitante de la Corona, así como a un carácter fiero, salvaje y bárbaro:

Furthermore, in Bulgaria "Catalan" and "son of Catalan" mean "evil man without a soul, torturer". [...] In this areas, the term "Catalan" was used as an insult even in the first half of the twentieth century ${ }^{25}$.

Realmente la "Gran Compañía Catalana" era la "Compañía franca", pues la componían hombres libres, "de alquiler" (mercenarios, en defini- 
tiva), y esa "venganza catalana" respondía en última instancia a intereses políticos y económicos. Sin embargo, acabarán por gestar una imagen en la conciencia colectiva de los territorios del Mediterráneo oriental, que se concretarán en falseamientos y generalidades a toda una sociedad, entre ellas el grito que se relata en la crónica, el famoso "Desperta ferres!" o el "Aragó! Aragó!" Y, sin embargo, el propio Ramón Muntaner señala que los que gritaron eso fueron "todos los francos" 26 .

A todo ello se le añadirá el carácter socioeconómico derivado del resto de empresas mediterráneas, en este caso comerciales. La imagen que se verá de los comerciantes peninsulares llamados "catalanes" será negativamente equiparable a estas actuaciones: el poeta Pontano afirma en el siglo XV que "a Catalano mercatore muttum non accipere"27. La tensión aumentará con la elección de Calixto III (Alonso de Borja) en 1455 y Alejandro VI (Rodrigo de Borja) en 1492, ambos pertenecientes a la familia Borja, o Borgia, procedentes de Játiva, en Valencia; sin embargo, el embajador de Florencia, tras ser elegido Alonso de Borja como nuevo papa, escribirá: "Regnano Chatalani e sa dio come la loro natura ci si confia" 28 , tachando pues a la "conveniencia de su carácter" y entendiendo como "catalanes" a todo habitante de la Corona ${ }^{29}$.

Observamos un primer ejemplo de supeditación aragonesa dentro de la propia Corona con respecto a los condados catalanes. Precisamente, será en el siglo XIV, en su momento de máxima expansión, cuando la Corona viva su momento más crítico, derivado de la llamada guerra de los Dos Pedros, Pedro I de Castilla (1334-1369) y Pedro IV de Aragón (1319-1387): en 1362, las tropas castellanas habían invadido prácticamente todo el reino de Aragón, y en una medida desesperada, Pedro IV creará una institución que aún hoy en día pervive, las generalidades ${ }^{30}$. Debido a la situación de invasión, y la bancarrota del reino, el monarca decide instaurar un arancel fronterizo, con control de las llamadas diputaciones, con los diputados del General, que invertirían lo recaudado íntegramente en financiar la guerra. Estos aranceles se cobrarían tanto en las fronteras de la Corona con los territorios exógenos, como entre las fronteras internas, es decir, de Aragón-

26. R. Muntaner (1860), 395-396.

27. S. Arnoldsson (1960), 17.

28. Ibidem, 18.

29. Cuando Calixto III muera en 1458 , se producirá una persecución y matanza de los "catalanes", es decir, las personas procedentes de la Península, instalados en Roma durante su pontificado.

30. Á. Canellas Vicente (1979), 4-5. 
Valencia, Aragón-Cataluña, Cataluña-Valencia ${ }^{31}$.

Estas fronteras arancelarias también suponían una frontera identitaria, ya que, aunque todos los territorios que conformaban la Corona estaban sometidos al rey de Aragón, no existía un sentimiento de unidad como tal. En la segunda mitad del siglo XV, durante el reinado de Juan II (1458-1479), e incluso en el de Fernando II (1479-1516), encontramos dos ejemplos de ello: en las Cortes de Alcañiz de 1436, y confirmado en las Cortes de Monzón de 1469-1470, se establecerá un fuero por el que los cargos en Aragón, así como en Cataluña, solo podrán ejercerse por los naturales de dichos territorios ${ }^{32}$. El segundo caso sucedió en 1482, cuando Fernando II nombró virrey al catalán Juan Ramón Folch (1446-1513), situándose como contrafuero al atentar contra esa naturalidad de los oficiales ${ }^{33}$. Si ello ocurría dentro de una Corona centenaria, no se puede aplicar un sentimiento hispano de unidad tras el matrimonio dinástico de 1469. De hecho, estos ejemplos nos sitúan en un paralelismo con el llamado "pleito del virrey extranjero", que afectará a Carlos I y a su hijo Felipe, en los inicios de la Monarquía Hispánica ${ }^{34}$.

\section{ENTRE EL ALBA Y EL OCASO: ARAGÓN Y LA MONARQUÍA HISPÁNICA}

Iniciado el siglo XV, Aragón viviría una nueva crisis, esta vez dinástica, al fallecer Martín I sin descendencia, dando lugar a un breve interregno (1410-1412). A pesar de que las instituciones y fueros aragoneses actuaron por superar la crisis de forma pacífica, las tensiones nobiliarias, arrastradas ya desde el siglo anterior, hicieron complicada la tarea ${ }^{35}$. Finalmente, tras la Concordia de Alcañiz (15 de febrero de 1412) se alcanzaría la deliberación de los nueve compromisarios, que, reunidos en Caspe, nombraron el 28 de junio de ese mismo año a Fernando de Antequera, de la dinastía Trastámara, hijo de Leonor de Aragón, y por tanto nieto de Pedro IV ${ }^{36}$. La dinastía trastamarista trajo la tradición del autoritarismo monárquico, consolidándose en el reinado de Juan II, cuando se producirá, además, una

31. J. Á. Sesma Muñoz (1992), mapas 1 y 2.

32. E. Sarasa Sánchez (1979), 81-82.

33. E. Sarasa SÁnchez (1992), 210.

34. L. González Antón (1986).

35. E. Sarasa Sánchez (1989).

36. J. Abella (2011), 89.

(C) Baetica. Estudios Historia Moderna y Contemporánea, 39, 2019, 75-92. Facultad de Filosofia y Letras, Universidad de Málaga. Departamento de Historia Moderna y Contemporánea 
guerra civil, siguiendo la estela castellana: el príncipe Carlos de Viana trató de arrebatar los derechos al trono de su hermano, el futuro Fernando II, quien poseía el título de duque de Montblanch, honor reservado al heredero a la Corona, y que finalizaría con la Concordia de Barcelona de $1461^{37}$.

Fernando de Aragón continuará con la política matrimonial, que más tarde ejecutó con sus hijos e hijas, al casarse, en secreto, en 1469 en Valladolid con Isabel, cuyo reinado conjunto será el momento de mayor ambigüedad política en el reino y Corona de Aragón. La intervención aragonesa en los asuntos castellanos será decisiva para la evolución de ambas coronas, pero especialmente para Castilla: las tropas aragonesas lucharon en momentos tan decisivos como la guerra civil castellana (1475-1479), que aseguró el ascenso de Isabel al trono de Castilla, o la guerra de Granada (1482-1492), que puso fin a la Reconquista peninsular. Fernando el Católico, coronado como Fernando II de Aragón en 1479, y nombrado Fernando V de Castilla por la Concordia de Segovia de 1475, concebiría a Castilla como fundamental para la política peninsular (ocupaba $2 / 3$ partes de la superficie y contenía el $85 \%$ de la población), afirmando que: "No hay reinar sin Castilla" 38 . Incluso tras la conquista de Navarra en 1512, y a pesar de la tradición que la unía con Aragón, el propio Fernando el Católico ordenó que fuese incluida dentro de la Corona de Castilla, aunque el escudo posterior a la conquista diera muestras de la verdadera intención del rey Católico de que Navarra estuviera dentro de la órbita aragonesa ${ }^{39}$.

El propio monarca "de sus 37 años como rey de Aragón, sólo cuatro residió en sus estados patrimoniales" ${ }^{\prime 4}, \mathrm{y}$, sin embargo, siempre mantendría los intereses aragoneses como un fin primordial, visualizado en su propio matrimonio con Germana de Foix para conseguir un heredero de la Corona aragonesa, tras la muerte de Isabel. Pero, de esta política, sobresalen los pactos matrimoniales de sus hijos, que realizó durante su reinado con las potencias europeas para aislar a Francia frente a su tentativa expansiva mediterránea, especialmente en Italia: la primogénita, Isabel, fue desposada en 1490 con el príncipe Alfonso de Portugal, el cual moriría al año siguiente, acordándose un nuevo enlace con el heredero Manuel, en 1496; María acabaría casándose en 1500 con Manuel de Portugal tras enviudar de Isabel. Catalina viviría un suceso parecido al de su hermana Isabel, al

37. A. Rubio Vela (2016),14-39.

38. A. Floristán Imízcoz (2016), 135.

39. F. Menéndez Pidal de Navascués (2005), 123.

40. A. Floristán Imízcoz (2016), 137. 
casarse en 1501 con Arturo de Gales, que falleció al año siguiente, por lo que acabaría casándose en 1509 con Enrique VIII de Inglaterra. Por su parte, los hermanos Juana y Juan vivirían en 1497 un matrimonio cruzado con Felipe y Margarita, hijos del emperador Maximiliano y María de Borgoña, aunque de ello hablaremos más adelante.

Este último caso es el más importante por su doble intencionalidad: por un lado, con ello se iniciaba el llamado "método de Maximiliano"41, con el que, a través de estos "matrimonios cruzados", extendía la presencia de los Habsburgo en las principales cortes europeas. A su vez, Fernando II estableció una red de alianzas por el occidente y centro del Viejo Mundo, aislando política y militarmente a la gran rival aragonesa, Francia, a la par que consiguió que el heredero último de esta nueva dinastía hispana reuniera en su persona un gran poder político y territorial ${ }^{42}$.

Si el matrimonio cruzado de los hijos de los Reyes Católicos con los hijos de Maximiliano y María de Borgoña supuso una especie de "ensayo", no podemos afirmarlo con seguridad. Desde luego, fue un preámbulo de toda un política imitada y llevada a cabo en los siglos posteriores por las cortes europeas con fines muy dispares. De esta forma, se alcanzaba el máximo ejercicio pragmático de una actividad matrimonial que no suponía una innovación en las relaciones político-estratégicas. Sin embargo, la concreción en torno a un reforzamiento matrimonial recíproco, en tanto a buscar un doble acuerdo matrimonial sí va a iniciar una nueva forma de consolidar las alianzas dinásticas ${ }^{43}$.

Con ello, y quedando Juana como última heredera, tras la muerte de su hermano, y el fallido matrimonio de Fernando con Germana de Foix, el hijo de la nueva reina con Felipe de Borgoña sería heredero universal de todos los territorios y posesiones de los Reyes Católicos y el empera-

\section{Ibidem, 55.}

42. J. I Ortega Cervigon (2018).

43. Al respecto de ello, el historiador Bartolomé Bennassar definirá los matrimonios cruzados como "las uniones simultáneas (o casi) entre hermanos y hermanas, o tíos y sobrinas, procedentes de las dos ramas" (vid. B, Bennassar (2017), 56). Aunque estas "dos ramas", con el tiempo, terminarán por confluir en las de una misma dinastía, es decir, hasta el reinado de Felipe II encontramos matrimonios cruzados entre figuras con antepasados comunes, pero de diferentes casas dinásticas. Un caso muy evidente será el doble matrimonio de Carlos V y su hermana Catalina, con Isabel y Juan III de Portugal, respectivamente, ya que, aunque los contrayentes tuvieran parentesco, no dejaban de ser de dos líneas diferentes, como fueron los Habsburgo de la Monarquía Hispánica y la Casa de Avís portuguesa. 
dor Maximiliano. Carlos, intitulado como I de España y V de Alemania, concentraría en su persona un poder hasta ahora desconocido: los reinos peninsulares, salvo Portugal, las posesiones mediterráneas, el derecho al trono imperial y la iniciada expansión atlántica.

Sin embargo, todos los procesos hasta ahora vistos se concretarán en su hijo Felipe: territorialmente, completó una unificación política peninsular, al nombrarse rey de Portugal en 1580; prosiguió la expansión americana, y ahora también del Pacífico, y las posesiones del Mediterráneo fueron fundamentales para su lucha contra los turcos. A su vez, las tensiones en Aragón irán en aumento: cuando todavía era príncipe, durante su matrimonio con María I de Inglaterra, tuvo que advertir en varias ocasiones desde Londres al emperador sobre los problemas de nombrar castellanos para cargos en Aragón ${ }^{44}$, o por conflictos entre los territorios de la Corona ${ }^{45}$. Estos conflictos internos culminarán en las Alteraciones de Aragón, que constituyen un momento de decrecimiento de la autonomía aragonesa: ya en estos momentos se observa una mentalidad existente, en críticas contra esta imagen de unidad castellana:

Lúcio: Y què pensau, senyors? La major part dels castellans gosen dir públicament que aquesta nostra provincia no és Espanya y per ço que nosaltres no som verdaders espanyols (...) aquesta nostra provincia no sols és Espanya mas és la millor Espanya (...) Açò és tan clar y tan que no y a home que gens lletrat sía, que ignore ${ }^{46}$.

El propio autor se lamentaría, no solo de este hecho, sino de la necesidad de afirmar este error, por lo que exhortaba a que "tampoch lo ignoren los castellans, mas per no donar-nos lo que és nostre no sols ho volen ignorar mas volen-ho negar" ${ }^{\prime 7}$. En estos momentos, el poder filipino se haya centralizado en torno a Madrid, y las tensiones con las instituciones aragonesas irían en aumento, hasta el proceso de Antonio Pérez que daría lugar al conflicto con el monarca en la década de 1590, y condujo a una merma de las capacidades del reino de Aragón.

44. Archivo General de Simancas (AGS), Consejo de Estado, legajo 808, doc. 80, 2 fols. Carta del Príncipe al Emperador sobre asuntos de los fueros de Aragón, 1554.

45. AGS, Consejo de Estado, legajo 809, doc. 18. Relación de lo que el serenísimo Príncipe escribió al Emperador, sobre los asuntos de Ribagorza, s. a.

46. C. Despuig (1557), 102.

47. Ibidem. 


\section{CONCLUSIONES}

El 9 de diciembre de 1493, Cristóbal Colón descubría una nueva isla en su deriva náutica por las aguas del Caribe. En las anotaciones de su cuaderno de bitácora describe la geografía de esa isla, y señala que posee las vegas "más hermosas del mundo y cuasi semejables a las tierras de Castilla", lo que le llevó a nombrar "a la dicha isla la isla Española"48. La historia de Aragón y Castilla tuvieron un desarrollo desigual, pero paralelo: ambas Coronas se configurarán como tales a lo largo de los siglos XII y XIII, cuando los diferentes territorios de León y Castilla se vuelvan indivisibles, y los reyes de Aragón estabilicen sus fueros e instituciones, y configuren una complejidad territorial en el Levante y el Mediterráneo occidental. Sin embargo, podemos establecer tres ideas fundamentales que remarcan la personalidad institucional e importancia política de la historia aragonesa en el desarrollo general de la Península y de Europa.

En primer lugar, como hemos visto, la historia de Aragón es más compleja: desde la herencia de Ramiro Sánchez hasta la herencia recibida por Carlos I y su hijo Felipe, las instituciones aragonesas sufrieron una continua transformación y adaptación circunstancial, en sí misma y dentro de una entidad como sería la Monarquía Hispánica. Tanto es así que al aforismo con el que hemos empezado este artículo podríamos añadirle una idea más: en Aragón no hubo leyes antes que reyes, porque ni siquiera tuvo reyes, al menos no de una dinastía original de Aragón. Si repasamos su trayectoria, la génesis aragonesa se fundamenta en una herencia navarra, y los primeros gobernantes hasta Petronila tuvieron esta ascendencia. Con la unión matrimonial entre la hija de Ramiro II y el conde Ramón Berenguer IV, se inicia una nueva dinastía con sangre condal, más allá de considerar si el conde de Barcelona se incorporó a la casa de su mujer, y no viceversa, bajo la institución del "casamiento en casa"49. Sea como fuere, este linaje perduraría hasta el Compromiso de Caspe, donde el nuevo rey será Trastámara, y, por tanto, de origen castellano. El matrimonio entre Fernando el Católico e Isabel traería la unión de ambas ramas dinásticas, y su política entroncaría a los Trastámara con los Habsburgo, que reinarían la nueva Monarquía Hispánica hasta que, finalmente, y esta vez sin compromiso pacífico, la ausencia de progenie llevaría a una guerra de sucesión donde se impondría lo ya dispuesto en el testamento carolino, la dinastía borbónica.

48. C. Colón (1985), 96.

49. J. Serrano Daura (1998). 
En segundo lugar, la ausencia real de una dinastía natural del territorio aragonés no resta su trascendencia como auténtica configuradora de la futura Monarquía Hispánica: la división de la herencia de Sancho III supuso la configuración de dos líneas de expansión reconquistadora, la castellana al oeste y la aragonesa en el Levante, dando lugar a numerosos tratados y conflictos, y generando una evolución desigual. Cuando ambas líneas se juntaron en la unión dinástica de 1469 , la política territorial de ambos monarcas siguió autónoma: el objetivo de Castilla fue poner fin a la Reconquista y propiciar una expansión atlántica en detrimento portugués; la línea aragonesa, defender sus objetivos en el Mediterráneo frente a las pretensiones francesas. Castilla solo necesitó financiación, así como la actuación de contingentes aragoneses, mientras que la segunda línea adquirió una mayor complejidad en el mapa político-territorial. La política matrimonial que ideó Fernando II buscaba el aislamiento de Francia en el panorama europeo, y dichos casamientos entre los hijos de los Reyes Católicos y las dinastías europeas construyeron la política imperial posterior. No importaba cómo evolucionaran: el matrimonio cruzado entre Juana y Felipe y Juan y Margarita aseguraba una unión patrimonial Trastámara-Habsburgo en un heredero, tanto de las Coronas peninsulares, como postulable al Sacro Imperio Romano Germánico. De esta forma, fue la política aragonesa la que acabó diseñando el futuro mapa político-territorial ibérico, europeo y global.

En tercer lugar, para evitar alargar demasiado este breve repaso por la historia de Aragón, he analizado un período cronológico bastante significativo, deteniéndome en la etapa del Rey Prudente. Sin embargo, aquí subyace un elemento de gran poder simbólico, que explica por qué me he detenido en este monarca. Aunque en la política filipina observamos una creciente centralización política, existe un elemento ideológico de mayor peso, que todavía hoy perdura, incluso en los círculos académicos: la intitulación de Felipe II constituye el inicio de un elemento muy discreto, en tanto que Felipe II de España era en realidad Felipe II de Castilla y I de Aragón, lo que revela la evidente reducción aragonesa, tomando a Castilla como el conjunto de España

A este respecto, ya a finales del siglo XV y principios del siglo XVI, comenzó a circular un cancionero, atribuido a Juan Fernández de Híjar, en el que se repasaban los diferentes personajes y acontecimientos que sucedieron en los distintos reinos peninsulares. Al hablar de Alfonso I de Asturias (693-757), el autor aprovecha para vincularlo con la tradición alfonsina, es decir, menciona a los numerosos reyes que han tenido el nombre de Alfonso, y señala cómo "Todos los reyes d'España / que Alfonsos fueron 
llamados" fueron monarcas con grandes virtudes, y es en este punto cuando apunta una idea muy significativa:

Non digo singularmente / que en Castilla y Leon / fue este nonbre excelente, / mas Portogal e Aragon, / reynos de aquesta naçion, / quantos Alfonsos ouieron / por virtudes floresçieron / e floresçen los que oy sonodo ${ }^{50}$.

Ciertamente, este romance entronca muy bien la "unificada" intitulación filipina con la alfonsina, pues, aunque Juan Fernández de Híjar reconoce la existencia de "Alfonsos" en todos los reinos peninsulares, la tradición áulica continuó la ordinación castellana, y los dos Alfonso desde el siglo XIV, se nombran Alfonso XII y Alfonso XIII, estableciendo una conexión entre la ya existente "unidad teórica" en las nomenclaturas de los Austrias con la Nueva Planta borbónica que se supuso la supresión práctica de las instituciones de la Corona de Aragón.

Tanto la supeditación (política e ideológica) castellana, como la definitiva guerra de Sucesión en el siglo XVIII han contribuido al aislamiento periférico de la historia de Aragón, y ello ha conducido a una ausencia de un profundo análisis sobre la importancia aragonesa en el panorama ibérico y europeo. A través de este artículo se ha podido comprobar cómo nada en la Historia puede ser visto como una certera verdad o una absoluta falsedad, quedando todavía muchas páginas por desvelar de este extraordinario pasado.

\section{BIBLIOGRAFÍA}

Abella, Juan (2011), "De Martín I a Fernando I. Itinerario de un compromiso", en J. A. Sesma Muñoz (dir.), La Corona de Aragón en el centro de su historia. El Interregno y el Compromiso de Caspe (1410-1412), Gobierno de Aragón, Zaragoza, pp. 61-94.

Alvira Cabrer, Martín (2010), "Después de Las Navas de Tolosa y antes de Bouvines. La batalla de Muret (1213) y sus consecuencias", en 1212-1214: El trienio que hizo a Europa (Actas de la XXXVII Semana de Estudios Medievales de Estella. 19 al 23 de julio de 2010), Institución Príncipe de Viana, Pamplona, pp. 85-112

Alvira Cabrer, Martín, Mace, Laurent y Smith, Damian J. (2009), "Le temps de la Grande Couronne d'Aragon du roi Pierre le Catholique. À propos de deux documents relatifs à l'abbaye de Poblet (février de septembre 1213)", Annales du Midi, 121, pp. 5-22.

Arco, Ricardo del (1930), Archivos históricos del Alto Aragón, Universidad, Zaragoza.

50. J. M. AzÁceta (1956), 270.

(C) Baetica. Estudios Historia Moderna y Contemporánea, 39, 2019, 75-92.

Facultad de Filosofia y Letras, Universidad de Málaga. Departamento de Historia Moderna y Contemporánea 
Arnoldsson, Sverker (1960), La Leyenda Negra. Estudios sobre sus orígenes, Göteborg Universitets Årsskrift, Göteborg.

AzÁceta, José María (1959), Cancionero de Juan Fernández de Híjar, Consejo Superior de Investigaciones Científicas, Madrid.

Benassar, Bartolomé (2017), Reinas y princesas del Renacimiento a la Ilustración: el lecho, el poder y la muerte, Editorial Pidós, Barcelona.

Blancas, Jerónimo de (1588), Aragonensium rerum commentarii, Laurentium Robles \& Didacum fratres, Caesaraugustae.

Canellas Vicente, Ángel (1979), Instituciones aragonesas de antaño: La Diputación del Reino, Diputación Provincial-Institución "Fernando el Católico", Zaragoza.

Colón, Cristóbal (1985), Diario. Relaciones de viajes, SARPE, Madrid.

Despuig, Cristòfor (1557), Los Col-loquis de la insigne ciutat de Tortosa, Universidad de Barcelona y Curial, Barcelona.

Floristán Imízcoz, Alfredo (2016), "La unión de Castilla y Aragón. Los Reyes Católicos (1474-1516), en A. Floristán Imízcoz (coord.), Historia de España en la Edad Moderna, Ariel, Barcelona.

Gallinari, Luciano y Martí Sentañes, Esther (2017), “The Medieval Heritage: Islands and Territories with a Specific Identity?", en F. SABATÉ (cord.), The Crown of Aragon: a Singular Mediterranean Empire, Brill, Leiden-Boston.

García Fitz, Fernando y Novoa Portela, Feliciano (2015), Cruzados en la Reconquista, Marcial Pons Historia, Madrid.

Gascón Pérez, Jesús (2010), Alzar banderas contra su Rey: la rebelión aragonesa de 1591 contra Felipe II, Prensas Universitarias, Zaragoza.

Giesey, Ralph E. (1968), If not, not. The oath of the aragonese and the legendary laws of Sobrarbe, Princeton University Press, Princeton (Nueva Jersey).

GonzÁlez Antón, Luis (1986), "La monarquía y el reino de Aragón en el siglo XVI: consideraciones en torno al pleito del virrey extranjero", Príncipe de Viana. Anejo, 2-3, pp. 251-268.

GonzÁlez Jiménez, Manuel (2000), “Re-conquista? Un estado de la cuestión”, en E. Benito Ruano (ed.), Tópicos y realidades de la Edad Media, vol. 1, Real Academia de la Historia, Madrid, pp. 155-178.

Leonardo de Argensola, Lupercio (1808), Información de los sucesos del Reino de Aragón en los años 1590 y 1591, en que se advierte de los yerros de algunos autores, Imprenta Real, Madrid.

López Medel, Jesús (2016), Escrito en Aragón: historia y derecho, hombres, espiritualidad, cultura, educación y turismo, libros, Diputación Provincial, Zaragoza.

Martínez Díez, Gonzalo (2004), El Condado de Castilla, Junta de Castilla y León, Valladolid.

Martínez y Herero, Bartolomé (1866), Sobrarbe y Aragón. Estudios históricos sobre la fundación y progreso de estos reinos hasta que se agregó á los mismos el condado de Barcelona, Imprenta de la Perseverancia, Zaragoza. 
Menéndez Pidal de Navascués, Faustino (2005), “Tanto monta. El escudo de los Reyes Católicos", en L. SuÁrez Fernández (coord.), Isabel la Católica vista desde la Academia, Real Academia de la Historia de España, Madrid.

Molina Molina, Ángel Luis (1997), "El Reino de Murcia durante la dominación aragonesa (1296-1305)", Anales de la Universidad de Alicante. Historia medieval, 11, pp. 265-272.

Muntaner, Ramón (1860), Crónica catalana, Imp. de Jaime Jepús, Barcelona. Edición bilingüe.

OnNis, Ramona (2016), Sergio Atzeni. Écrivain postcolonial, Editions L'Harmattan, París.

Ortega Cervigon, José Ignacio (2018), Breve historia de Carlos V, Ediciones Nowtilus, Colección Breve Historia, Madrid.

Quadrado, José María (1850), Historia de la conquista de Mallorca. Crónicas inéditas de Marsilio y de Desclot en su testo lemosin, vertida la primera al castellano y adicionada con numerosas notas y documentos, Estevan Trias, Palma de Mallorca.

Roquebert, Michel (2002), Histoire des Cathares: Hérésie, Croisade, Inquisition $d u X I^{e}$ au XIV siècle, Perrin, París.

Rubio Vela, Agustín (2016), Valencia, el príncipe de Viana y Juan II: un patriciado ante la crisis política de la Monarquía (1460-1461), Papallona, Valencia.

Sarasa SÁnchez, Esteban (1979), Las Cortes de Aragón en la Edad Media, Guara Editorial, Zaragoza.

— (1989), "La sociedad aragonesa en la Baja Edad Media", Historia de Aragón, 2, pp. 327-344.

- (1996), Fernando II de Aragón, el Rey Católico, Institución "Fernando el Católico", Zaragoza.

SÉNAC, Philippe (2000), La frontière et les hommes, VIII $-X I I^{e}$ siècle: le peuplement musulman au nord de l'Ebre et les débuts de la reconquête aragonaise, Maisonneuve et Larose, París.

Serrano Daura, Josep (1998), "La donación de Ramiro II de Aragón a Ramón Berenguer IV de Barcelona, de 1137, y la institución del casamiento en casa", Hidalguía: la revista de genealogía, nobleza y armas, 270, pp. 709-719.

Sesma Muñoz, José Ángel (1992), "Fronteras económicas y generalidades en el Aragón medieval", en Atlas de Historia de Aragón, Institución "Fernando el Católico", Zaragoza. URL: https://ifc.dpz.es/webs/atlash/indice_epocas/ medieval/57.htm (consulta: 27/11/2019)

Smith, Damian J. (2014), "Los orígenes y el significado de la Batalla de Muret", Revista Chilena de Estudios Medievales, 5, pp. 73-90.

Urbieto Arteta, Antonio (1987), Historia de Aragón. Creación y desarrollo de la Corona de Aragón, Anubar, Zaragoza.

Utrilla Utrilla, Juan Fernando (2005), “Corona de Aragón”, en M. a del P. RÁbade Obradó, E. Ramírez Vaquero y J. F. Utrilla Utrilla (eds.)”, Historia de España VII: Historia Medieval. La dinámica política, Istmo, Madrid, pp. 283-495. 
- (2009), "La nobleza aragonesa y el Estado en el siglo XIII: composición, jerarquización y comportamientos políticos", en E. SARASA SÁNCHEZ (coord.), La sociedad en Aragón y Cataluña en el reinado de Jaime I (1213-1276), Institución "Fernando el Católico", Zaragoza, pp. 199-218.

- (1988), "Los territorios de la Corona de Aragón: la expansión por el Mediterráneo (1229-1479) y sus derivaciones", en G. FATÁs CABeZa (dir.), Aragón en el mundo, Caja de Ahorros de la Inmaculada de Aragón, Zaragoza, pp. 99-112. 